\title{
NUTRITIONAL STATUS AMONG THE PRIMARY SCHOOL CHILDREN IN A SELECTED RURAL COMMUNITY
}

\author{
Ara $\mathbf{R}^{1}$, Hoque $\mathbf{S R}^{2}$, Adhikary $\mathbf{M}^{3}$, Uddin $\mathbf{M N}^{4}$, Mahmood $\mathbf{A R}^{5}$, Ferdousi SK
}

\begin{abstract}
:
The study was conducted among 345 school children out of 1500 male and female students in the primary school of Sreepur Upazila under Gazipur district during the period of February to June 2010 irrespective of sex with a view to assess their nutritional status. In this study the prevalence of malnutrition were as follows $24.34 \%$ mild malnutrition, $34.2 \%$ moderate malnutrition and $24.06 \%$ were severe malnutrition. Regarding occupation of their parent's 29.9\% father was businessman, 24-9\% service holders, 24.9\% industrial workers while 79.9\% mothers were housewives. Regarding educational status $30.4 \%$ fathers and $31.3 \%$ mothers were illiterate. Most of the student (about 95\%) came to school on foot. Among different types of game played by them cricket was the most popular one (40\%). Regarding household work $58 \%$ works regularly among them $82.5 \%$ worked half an hour to one hour daily. Among the respondent $84 \%$ were completely immunized, three fourth of the respondent (76\%) used tube well as source of drinking water, and 95\% used sanitary latrine. Regarding dietary intake 93\% respondent took meal thrice a day containing carbohydrate, protein and fat at least once a day.
\end{abstract}

Key words: malnutrition, weight for height index, physical activity.

J Dhaka Med Coll. 2011; 20(1) : 97-101.

\section{Introduction:}

Nutrition is an integral part of physiology, biochemistry, pharmacology, medicine, surgery, public health, obstetrics, gynecology and pediatrics. Investments in nutrition can serve sectoral goals, and at the same time can enable nutrition actions to increase larger resources and capacity flows, thereby accelerating reductions in malnutrition. According to WHO criteria, $52 \%$ of young children in under-developed countries are considered normal, while $48 \%$ of them are malnourished and $10 \%$ of them are severely malnourished. Stunting reflects the cumulative effects of chronically insufficient food intake and recurrent infections. On the other hand, wasting can develop very rapidly as a result of sudden reductions in food consumption, such as starvation. ${ }^{1}$
Globally, malnutrition among school age children is becoming a major public health concern. More than 200 million school age children are stunted and if no action is taken, and at this rate, about 1 billion stunted school children will be growing up by 2020 with impaired physical and mental development. ${ }^{2}$ In one of the largest studies in anthropometric status of school age children in low income countries found the overall prevalence of stunting and underweight to be high in all the countries ranging from $48 \%$ to $56 \%$ for stunting and from $34 \%$ to $62 \%$ for underweight. ${ }^{3}$ It is therefore evident that a significant percentage of school age children suffer from malnutrition, affecting their health and nutritional status, and school academic performance. ${ }^{4}$

The school has been identified as a suitable place to implement nutrition education

1. Dr. Rowshan Ara, Assistant Professor, Department of community Medicine, Dhaka Medical College, Dhaka

2. Dr. Syeda Rumana Hoque, Medical Officer, Department of Community Medicine, Dhaka Medical College, Dhaka.

3. Dr. Minati Adhikary, Assistant Professor, Department of Community Medicine, Dhaka Medical College, Dhaka.

4. Brig. Gen. Md. Nasir Uddin, Chief Health Officer, Dhaka City Corporation, Dhaka.

5. Dr. Afzalur Rahman Mahmood, Lecturer, Department of Community Medicine, Dhaka Medical College, Dhaka.

6. Dr. Syeda Khaleda Ferdousi, Assistant Professor, Department of community Medicine, Dhaka Medical College, Dhaka.

Correspondence : Dr. Rowshan Ara, Assistant Professor, Department of community Medicine, Dhaka Medical College, Dhaka 
programmes because it has a systematic environment. The school age children estimated at least $24 \%$ of the population of developing countries and about $15 \%$ in industrialized countries. ${ }^{5} \mathrm{~A}$ major public health issue of our time is the epidemic of bad nutrition as the prevalence of cardiovascular diseases, hypertension, diabetes and certain cancers. Malnutrition has a significant effect not only on the individual but also on the country's economy. The economic cost of malnutrition to the country is estimated to be substantial. ${ }^{1}$

The consequences of Protein Energy Malnutrition (PEM) among school age children are retarded physical and mental development, which are associated with non-enrolment or late enrolment to school. ${ }^{6}$ Malnutrition impairs the immune system, making children more vulnerable to infections and less interested in the environment they live in, than are well nourished peers. The combination of malnutrition, infections and poor environmental sanitation affects their health and nutritional status thus reducing a child's learning opportunities. ${ }^{7}$

It is important to note that well nourished children brought up in a healthy nurturing environment, grow stronger, taller and become adults that are more productive, maintaining high levels of functionality and produce healthy offspring in the future. ${ }^{4}$

\section{Method:}

The present cross sectional study was conducted at Sreepur Model Government Primary school and Keoa Poschim Khondo Daroga Chala Register primary school of Sreepur upazila under Gazipur district from February to June 2010. The study population was fifteen hundred students of class 4 and class 5 . Out of fifteen hundred 345 students were interviewed and anthropometrically measured. The ages of the students were determined from the school register. Anthropometric measurements included height, weight and Mid Upper Arm Circumference. Weight was measured by the bathroom scale and Height was taken by measuring tape. Nutritional status was classified by using weight for height index. All the relevant information was recorded in a pre tested questionnaire. Statistical analysis was done by using SPSS windows package version 11. All the data expressed as mean and + SD.

\section{Result:}

In this study the mean age of the students was 10.5 years and the standard deviation was + 1.178 years (Table-I). Most of the students 96.8\% were Muslims and $2.9 \%$ were Hindus. Regarding education among the fathers $30.4 \%$ were illiterate, $31.6 \%$ received primary education, $24.1 \%$ fathers and $21.2 \%$ mothers had completed SSC examination. Regarding occupation of the parents $29.9 \%$ fathers were businessman, $24.9 \%$ were service holder, $18.6 \%$ workers, $9.9 \%$ farmers and $7 \%$ day labourers whereas $79.7 \%$ mothers were housewives, $13.6 \%$ service holders, $4.6 \%$ workers and $0.9 \%$ day labourers. This study revealed that $94.8 \%$ respondents went to school by walking and only $4.1 \%$ avail rickshaw and $1.2 \%$ avail cycle. Regarding meal intake 98\% respondents took meal thrice or more a day among them 93\% students took carbohydrate, protein and fat at least once daily. Milk and fruits intake were $31.9 \%$ and $30.1 \%$ respondents respectively. Regarding weight and height of the respondents mean weight was $27.18 \mathrm{~kg}$ with standard deviation $\pm 6.78 \mathrm{~kg}$ and mean height was $136.9 \mathrm{~cm}$ with standard deviation $\pm 8.57 \mathrm{~cm}$. MUAC of the most of the respondent (about 80\%) was in the range of 15 to $20 \mathrm{~cm}$ and their mean was $18.5 \mathrm{~cm}$ with SD $\pm 2.16 \mathrm{~cm}$. Nutritional status was categorized into six groups: obese, overweight, normal, mild malnutrition, moderate malnutrition and severe malnutrition. The study revealed that $24.3 \%$ were mildly malnourished $34.2 \%$ were moderately malnourished while severe malnourished were $24.06 \%$. Among the respondents $16.23 \%$ were of good nutrition and only $2 \%$ were of obese and overweight. Regarding immunization coverage $83 \%$ respondents were immunized completely while $15.4 \%$ were incomplete. Study revealed that three fourth of the respondent (76\%) used tube well water. It was also found that $94.8 \%$ respondents enjoyed the facility of using sanitary latrine (Table-II). In this study 40\% student played cricket and remaining enjoyed different type of games were running, skipping, football and kabady. Nutritional status was categorized into 5 groups. The result was presented in Fig.-1 
Table - I

Age and sex distribution of the respondents

\begin{tabular}{lcccc}
\hline Age (in year) / Sex & Boys & Girls & Total & \\
\hline 8 & $1(0.6)$ & $8(4.8)$ & $9(2.6)$ & \\
9 & $19(10.7)$ & $28(16.7)$ & $47(13.6)$ & \\
10 & $64(36.2)$ & $60(35.7)$ & $124(35.9)$ & Mean age \\
11 & $56(31.6)$ & $45(26.8)$ & $101(29.3)$ & 10.55 years \\
12 & $25(14.1)$ & $19(11.3)$ & $44(12.8)$ & +1.178 \\
13 & $10(5.6)$ & $4(2.4)$ & $14(4.1)$ & \\
14 & $2(1.1)$ & $4(2.4)$ & $6(1.7)$ & \\
\hline Total & $177(51.3)$ & $168(48.7)$ & $345(100)$ & \\
\hline
\end{tabular}

Table-II

Condition of basic sanitation and source of drinking water

\begin{tabular}{llcc}
\hline Variables & & $\begin{array}{c}\text { Number of } \\
\text { respondents }\end{array}$ & Percent \\
\hline Use of sanitary & Yes & 327 & 94.8 \\
latrine & No & 18 & 5.2 \\
& Total & 345 & 100 \\
Sources of & Tube well & 262 & 75.9 \\
drinking water & Supply water & 82 & 23.8 \\
& Pond & 1 & 0.3 \\
& Total & 345 & 100 \\
\hline
\end{tabular}

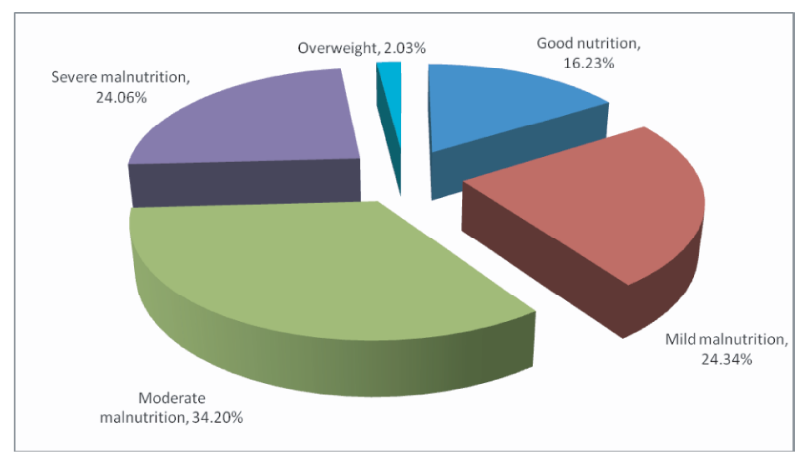

Fig.-1: Nutritional status of the respondents

\section{Discussion:}

This descriptive cross sectional study was done to assess the nutritional status among primary school children in a selected rural community. The study also explores the pattern of physical activities performed by them, the socio demographic characteristic of the respondent and the type of food consumed by them. In this study a total number of 345 students were interviewed in two primary school of Sreepur Upazila undr gazipur district. Anthropometric measurements of the respondents were done and nutritional status was classified by using weight for height index ${ }^{8}$. This study found that the mean height, weight and MUAC of the respondents were $136.9 \mathrm{~cm}, 27.8 \mathrm{~kg}$, and $18.5 \mathrm{~cm}$ respectively. This reflects out the better socioeconomic status of that community. This result is not consistent with the study conducted at Rachipur Karnataka among the primary school children where they found that their mean, height, weight and MUAC was $124.3 \mathrm{~cm}$, $20.90 \mathrm{~kg}$, and $15.65 \mathrm{~cm}$ respectively ${ }^{9}$. In this study among the respondents it was revealed that the percentage of respondents suffering from mild, moderate and severe malnutrition were $24.34 \%, 34.2 \%$ and $24.06 \%$ respectively. Also found that about $16.23 \%$ of the respondents were found to be normal whereas overweight and obese students constituted a minority about $2 \%$. This finding was in contrast to the Health Bulletin report, 2008 which showed that only $4.64 \%$ of the total number of school going children of Bangladesh was malnourished ${ }^{10}$. In this study a good findings regarding immunization coverage was revealed out that $84 \%$ respondent were fully immunized and only $15 \%$ immunization coverage were incomplete. This findings is consistent with the Bangladesh Demographic and Health survey 2007 , which reported that $82 \%$ of the primary school children had received all basic 
recommended vaccines i.e., BCG, Measles, 3 dosed DPT and polio ${ }^{11}$. This finding brings to our knowledge the success of EPI in bringing majority of the population under immunization coverage. Ongoing study reveals that 98\% respondents took meal thrice or more a day, among them 93\% students took carbohydrate, protein and fat at least once daily, but their milk and fruits intake were not satisfactory $31.3 \%$ and $30 \%$ respectively invariably they were deprived from having a balanced diet. Similar findings were observed in another study. ${ }^{12}$ This may be due to same socio economic and educational status. Cricket was the most popular game among the students $40 \%$, other types of games in which the students indulged were running, skipping, football and kabady. Study carried out in India among the school children of high socio economic status also found Cricket was the most practiced game among the students ${ }^{13}$. According to UNICEF physical activity is essential for better physical, mental and social development of child ${ }^{14}$. Study findings showed that nearly half of the respondents (58\%) helped their family in household work on an average 1 hour per day. Most of the respondents (95\%) came to school by foot. They also played different types of games like cricket, running, skipping, football etc. These findings showed that they are physically active. Evaluation of the source of drinking water of the students showed that $75.9 \%$ used tube well water and $23.8 \%$ used supply water. This finding is consistent to the BDHS report 2007 showed that 95.7\% rural households used tube well water ${ }^{11}$. The study revealed that among the fathers, $30.4 \%$ were illiterate, $31.6 \%$ had received primary education whereas $31.3 \%$ of the mothers were illiterate and $40.9 \%$ had received primary education. This clearly demonstrates the success of the provision of free female education programmed of the government. A negligible percentage $5.5 \%$ of fathers had graduate and $2.3 \%$ postgraduate whereas with the mothers HSC, graduation and post graduation was rarer still. This abrupt tapering in the educational status of the mothers was probably due to the rural tradition of early marriage in our country. This finding is consistent with the study conducted in Kenya revealed that fathers had more years of schooling than the mothers ${ }^{15}$. In spite of good immunization coverage, wide distribution of antihelminthics and vitamin A capsule, safe water supply and usage of sanitary latrine, the curse of malnutrition is prevailing; this may be due to illiteracy of the parents.

Conclusion: Since children at primary school age are in active growth period, deficiency of protein and energy would lead to failure of growth in terms of weight and height. So, the efforts for reducing malnutrition should be directed towards educating the parents about formulating a balance diet for their children. Also improvement of the socio-economic condition of the mass can help significantly. If the efforts of the government and nongovernment organizations are integrated and directed properly it can give amazing results within a short period of time.

\section{References:}

1. Source Book, Health, Nutrition \& Population sector, Government of the People's Republic of Bangladesh, Ministry of Health \& Family Welfare, Human Resources Management, Planning \& Development Unit.

2. Food \& Nutrition bulletin(Supplementary) UNICEF, 2006; 21(3): 6-17.

3. Drake L,Maier C, Jukes M and Patrikios A. School Age Children:their health \& Nutrition prepared for Partners in Child development, 2002

4. Chesire EJ, Orago ASS, Oteba LP, Echoka E. Determinants of under nutrition among school age children in a Nairobi Peri-urban slum. East Afr Med J 2008; 85:

5. Shariff ZM, Bond JT, Johson NE. Nutritional Status of Primary School Children from Low Income Households in Kuala Lumpur. Mal J Nutr. 2000; 6: 17-32

6. WHO. The World Health Report: Make every mother \& children count, France, WHO Library Cataloguing-in-publication data, 2005;1-9.

7. Evans JL, Myres RG and Ilfeld EM. Early Childhood Counts: A Programme Guide for Development, Washington D.C., The World Bank, 2000

8. Primary Health Care Issues: Growth Monitoring. American Public Health Association. 1981.

9. Bharati P, Itagi S, Megeri SN. Anthropometric measurements of school children of Raichur, Karnataka. J. Hum. Ecol. 2005; 18: 177-9. 
10. Health Bulletin 2008: Government of the People's Republic of Bangladesh, Ministry of Health \& Family Welfare.

11. Bangladesh Demographic and Health Survey, 2007.

12. Mariara JK, Ndenge GK, Mwabu K. Determinants of Children's Nutritional Status in Kenya: Evidence from Demographic and Health Surveys. J Afr Econ 2008; 18: 363-87.
13. Shah C, Diwan J, Rao P, Bhabhor M, Gokhle P, Mehta H. Assessment of Obesity in School Children. Calicut Med J. 2008; 6:

14. http:/www.unicef.org/sports/index23624.html

15. Meme MM, Kogi-Makau W, Muroki NM, Mwadime RK. Energy and protein intake and nutritional status of primary school children 5 to 10 years of age in schools with and without feeding programmes in Nyambene district, Kenya. Food and Nutrition Bulletin 1998; 8: 